\title{
Didactical Design Research untuk Mengembangkan Kompetensi Pedagogik Guru di Sekolah Dasar
}

\author{
Irfan Fauzi ${ }^{1)}$, Didi Suryadi ${ }^{1)}$ \\ Universitas Pendidikan Indonesia \\ *Corresponding author E-mail: if96@upi.edu
}

\begin{abstract}
Abstrak
Keywords: Didactical design research, kompetensi pedagogik, sekolah dasar

Salah satu kemampuan guru yang berkaitan dengan pedagogik adalah mampu membuat rencana pembelajaran efektif yang sesuai dengan kebutuhan siswa, untuk menciptakan hal itu dibutuhkan sebuah inovasi untuk mendesain pembelajaran. Didactical design research (DDR) dipandang sebagai sebuah paradigma inovasi pembelajaran dalam memberikan solusi atas permasalahan sulitnya guru dalam membuat rencana pembelajaran yang sesuai dengan kebutuhan siswa di kelas, selain itu didactical design research dipandang sebagai salah satu cara dalam mengembangkan kompetensi pedagogik guru, penelitian ini bertujuan untuk mengkaji paradigma DDR dalam menembangkan kompetensi pedagogik guru, metode yang digunakan dalam penelitian ini menggunakan kajian literatur dari berbagai sumber baik jurnal, buku, dan sumber lain yang mendukung. Penelitian ini diharapkan memberikan wawasan dan pengetahuan bagi penelitia dalam mengembangkan penelitian menggunakan didactical design research, selain itu penelitian ini diharapkan memberikan panduan kepada guru dalam membuat desain pembelajaran yang sesuai dengan kebutuhan siswa, sehingga proses pembelajaran tercipta dengan nyata dan bermakna.
\end{abstract}

Keywords: didactical design research, kompetensi pedagogik, sekolah dasar

\section{Abstract}

Keywords: didactical design research, pedagogical competence, elementary
One of the teacher's abilities related to pedagogics is being able to make effective learning plans that are appropriate to the needs of students, to create this it requires an innovation to design learning. Didactical design research $(D D R)$ is seen as a paradigm of learning innovation in providing solutions to the difficulties of teachers in making learning plans that fit the needs of students in the classroom, in addition to that didactical design research is seen as one way in developing teacher pedagogical competencies, this research aims To examine the DDR paradigm in developing teacher pedagogical competencies, the method used in this study uses literature review from various sources, both journals, books, and other supporting sources. This research is expected to provide insights and knowledge for researchers in developing research using didactical design research, besides this research is expected to provide guidance to teachers in making learning designs that are appropriate to students' needs, so that the learning process is created real and meaningful.

Keywords: didactical design research, pedagogical competence, elementary school 


\section{Pendahuluan}

Perubahan zaman terus berputar, Revolusi industri 4.0 yang diprakarsai oleh Negara Jerman terus disempurnakan, bahkan setelah itu muncul istilah baru yang dinamakan revolusi industri 5.0 atau society era 5.0 yang digagas oleh Negara Jepang dengan mengangkat tema human centersociety. Revolusi industri 4.0 ditandai dengan pesatnya kemajuan teknologi informasi seperti internet, big data, dan artificial intelligence. Sedangkan revolusi industri 5.0 dapat diartikan sebagai suatu konsep masyarakat yang berpusat pada manusia (human-centered) dan berbasis teknologi (technology-based). Konsep revolusi industri 5.0 telah menggabungkan unsur yang sangat penting di abad ini, yaitu manusia dan teknologi.

Abad 21 juga telah mendorong perubahan diberbagai bidang khususnya dalam bidang pendidikan. Pendidikan abad 21 memiliki tujuan untuk menciptakan insan yang kritis dalam intelektual, kreatif dalam pemikiran, etis dalam pergaulan, dan berkarakter dalam kehidupan (Abidin, 2015), disisi lain Trillling \& Fadel (2009) menjelaskan bahwa pembelajaran abad 21 harus berfokus pada empat keterampilan inti diantaranya adalah berfikir kritis dan pemecahan masalah (critical thinking and problem solving), kemampuan berkomunikasi (communication), kemampuan berkolaborasi (colloboration), dan kemampuan mencipta sesatu yang baru (creativity).

Pendidikan telah menjadi ujung tombak dalam membangun paradaban sebuah bangsa. Maka, untuk membangun peradaban yang beradab, dibutuhkan sistem pendidikan yang progresif dan maju. Menurut Rusman (2013) bahwa hal yang menjadi kunci keberhasilan sebuah pendidikan salah satunya dipegang oleh guru. Guru menjadi leading sector yang langsung bersentuhan dengan siswa di sekolah, dalam menjalankan profesinya guru harus dapat memastikan proses pembelajaran berlangsung dengan baik karena hal ini merupakan tanggungjawab dan profesionalisme bagi seorang guru.

Setidaknya minimal ada tiga tugas yang harus dilaksanakan guru berkaitan dengan kompetensi pedagogik diantaranya adalah merencanakan pembelajaran, mengimplementasikan rencana pembelajaran, dan mengevaluasi pembelajaran (Alawiyah, 2013). Proses pembelajaran menjadi bagian terpenting yang harus dijalankan guru di sekolah. Keberhasilan seorang siswa memahami konteks materi yang diajarkan tergantung sejauhmana proses pembelajaran dapat terlaksana dengan baik. Proses pembelajaran melibatkan berbagai aktivitas antara siswa, guru dan lingkungan pembelajaran itu sendiri, yang kemudian hal itu dikendalikan dalam rencana pembelajaran. Semakin matang guru merencanakan rencana pembelajaran, maka proses pembelajaran akan semakin baik. Callahn \& Clark (Zendrato, 2016) menyatakan bahwa mengajar tanpa persiapan secara tertulis akan menghasilkan ketidakefektifan pembelajaran, hal ini didasarkan karena guru tidak memikirkan secara detail terhadap apa yang akan dilakukan dan bagaimana melakukannya. Dengan demikan bahwa guru perlu menyusun rencana pembelajaran yang memandang situasi pembelajaran secara utuh dan menyeluruh sebagai suatu objek nyata, hal yang harus menjadi perhatian guru dalam membuat rencana pembelajaran adalah bagaimana melihat berbagai kemungkinan respon siswa baik yang bersifat didaktis maupun pedagogis untuk dapat diantisipasi sedemikian rupa, sehingga dalam proses 
pembelajarannya dapat menciptakan dinamika perubahan didaktis dan pedagogis yang sesuai dengan kapasitas, kebutuhan, serta percepatan proses belajar yang dialami siswa, apalagi jika melihat tahap perkembangan berpikir siswa sekolah dasar yang masih berada pada tahap operasional konkret, dimana proses pembelajarannya harus bersifat realistik sesuai dengan kondisi nyata yang dialami siswa. Akan tetapi kenyataanya bahwa rencana pembelajaran yang digunakan guru dinilai tidak sesuai dengan kondisi nyata siswa (Saputri \& Mawardi, 2017). Biasanya guru hanya menyusun rencana pembelajaran tanpa memperhatikan berbagai kemungkinan respon siswa yang muncul, hal inilah yang menjadi alasan sulitnya siswa dalam merespon guru dalam pembelajaran yang berakibat pada hilangnya semangat belajar sehingga siswa merasa bahwa dirinya tidak memiliki kemampuan belajar yang baik.

Didactical Design Research (DDR) versi Indonesia dikenalkan oleh Guru Besar Universitas Pendidikan Indonesia (Didi Suryadi) pada tahun 2010, filosofi yang mendasari DDR adalah pemahaman tentang bentuk-bentuk inovasi pendidikan dan upaya peneliti dalam menciptakan inovasi pendidikan (Gravemeijer \& Cobb, 2006).. Proses pembelajaran pada umumnya mempelajari tentang fenomena belajar dan mengajar yang terjadi antara guru, siswa dan materi/pengetahuan, lebih lanjut Manno (2006) menjelaskan bahwa aktivitas dalam proses pembelajaran digambarkan dalam segitiga guru-pengetahuan/materi-murid.

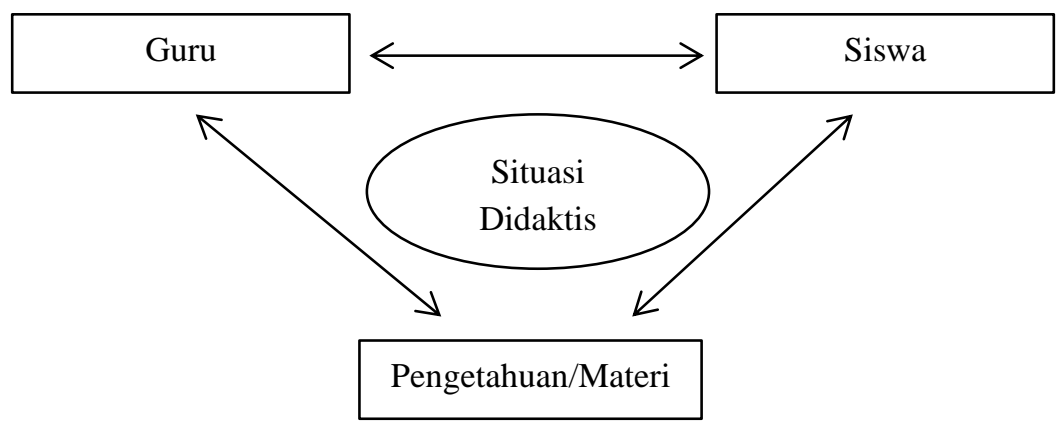

Gambar 1. Aktivitas dalam Proses Pembelajaran

Analisis segitiga ini telah dikenal sejak tahun 1982 ketika pertama kali muncul dalam karya Yves Chevallard, di mana kata "pengetahuan" berarti pengetahuan akademis, standar kurikulum dan objek penelitian. Pada bagaian ini peran guru adalah untuk memungkinkan transposisi didaktis diantaranya mengubah pengetahuan yang berasal dari dunia penelitian, menjadi pengetahuan yang harus disusun dalam perencanaan pembelajaran sampai kepada pengetahuan itu diajarkan

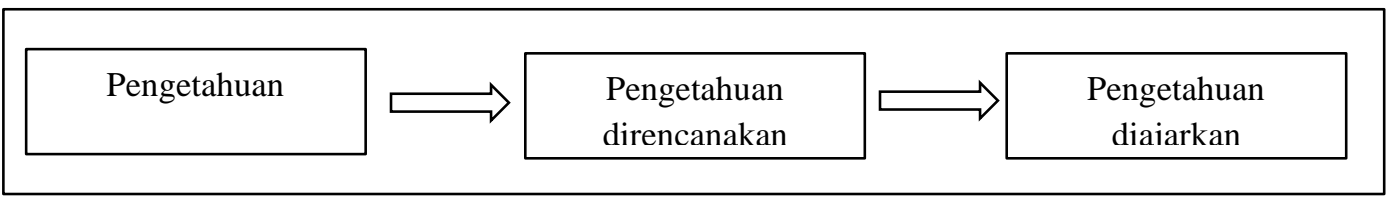

Gambar 2. Transposisi Didaktis 
Sementara itu, Suryadi (2010) adalah siswa, guru dan materi, ketiga hal ini menjelaskan bahwa untuk menciptakan proses merupakan elemen dasar dalam kegiatan pembelajaran yang efektif maka ada beberapa hal pembelajaran, ketiga elemen tersebut yang harus menjadi fokus perhatian, diantaranya digambarkan dalam situasi didaktis.

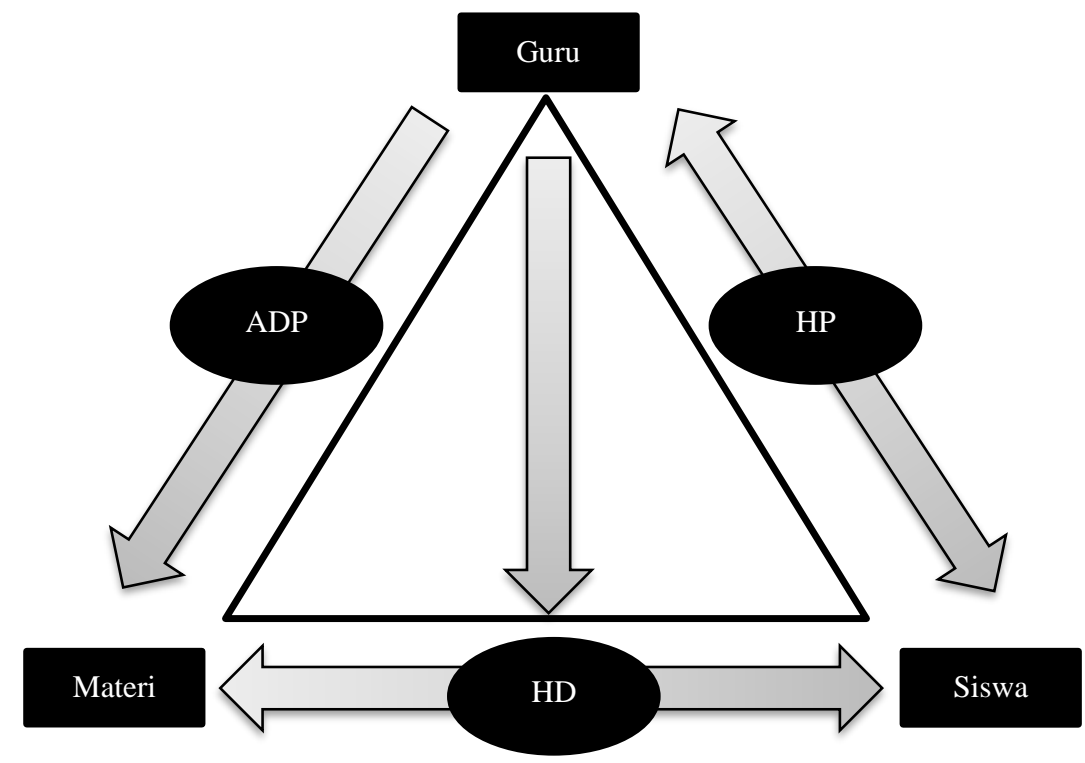

Keterangan:

Gambar 3. Tiga elemen dasar dalam pembelajaran (Suryadi, 2010)

HD : Hubungan didaktis

HP : Hubungan Pedagogis

ADP : Antisipasi Didaktis Pedagogis

Menurut Mulyana, Turmudi, \& Juandi (2014) bahwa peran utama dari seorang guru dalam konteks segitiga didaktis di atas adalah menciptakan situasi didaktis sehingga terjadi proses belajar dalam diri siswa.

Suryadi dalam (Martadiputra, 2013) memformulasikan sebuah didactical Design Research (DDR) dalam pengembangan bahan ajar melalui tiga tahap, diantaranya adalah

1. Analisis situasi didaktis yang dilakukan guru sebelum pembelajaran berupa pemikiran guru tentang prediksi dan antisipasi terhadap respons siswa yang akan muncul pada situasi didaktis yang akan dimunculkan pada saat pembelajaran.

2. Analisis metapedadidaktik yang dilakukan selama proses pembelajaran berupa kemampuan guru terkait dengan peristiwa pembelajaran untuk memandang komponen-komponen segitiga didaktis yang dimodifikasi, seperti antisipasi didaktis pedagogis (ADP), hubungan didaktis (HD), dan hubungan pedagogis (HP) sebagai suatu kesatuan yang utuh. Kemudian, guru mengembangkan tindakan sehingga 
tercipta situasi didaktis dan pedagogis yang sesuai dengan kebutuhan siswa, mengidentifikasi serta menganalisis respons siswa sebagai akibat tindakan didaktis maupun pedagogis yang dilakukan, dan melakukan tindakan didaktis dan pedagogis lanjutan berdasarkan hasil analisis respons siswa menuju pencapaian target pembelajaran.

3. Analisis retrosfektif, yakni analisis yang mengaitkan hasil analisis situasi didaktis hipotesis dengan hasil analisis metapedadidaktik berupa refleksi pasca pembelajaran.

Didactical design research menjadi salah satu cara dalam mengembangkan kompetensi pedagogik guru di sekolah dasar, maka dalam artikel ini akan mengkaji tentang kedudukan didactical design research untuk mengembangkan kompetensi pedagogik guru di sekolah dasar

\section{Metode}

Penelitian ini didasarkan pada hasil studi dari beberapa buku, jurnal dan ulasan literatur lainnya. Pengumpulan data yang digunakan dalam penelitian ini didasarkan pada metode studi literatur dengan melakukan studi review buku, literatur, dan catatan yang berkaitan dengan masalah yang diangkat (Nazir, 2013). Menurut (Komariah \& Satori, 2011) dijelaskan bahwa studi literatur adalah pendukung penelitian yang dimulai dari pandangan para ahli dalam menulis dalam bentuk buku referensi, jurnal, laporan penelitian atau karya ilmiah lainnya.

\section{Hasil dan Pembahasan}

\section{Peran Guru dalam Menciptakan Perencanaan Pembelajaran}

Guru memegang peranan penting dalam terlaksananya pembelajaran, dalam segitiga didaktis guru bukan hanya dituntut untuk menguasai materi terkait konteks pengetahuan yang akan diajarkan, tetapi harus memahami kondisi nyata siswa dan juga harus menciptakan situasi didaktis-pedagogis sehingga mendorong siswa untuk dapat belajar secara optimal. Terdapat dua hubungan yang terjadi dalam situasi didaktis, diantaranya adalah:

\section{Hubungan Guru-Materi}

Materi menjadi salah satu konten yang dimuat dalam perencanaan pembelajaran, sudah seharusnya guru memahami materi/pengetahuan yang akan diajarkan kepada siswa, karena hal itu menjadi tolak ukur siswa dalam memahami materi yang akan diajarkan. Beberapa hal yang harus dilakukan guru dalam memahami materi yang akan diajarkan kepada siswa adalah:

\section{Menganalisis Kurikulum}

Analisis kurikulum menjadi bagian hal yang penting bagi seorang guru terkait komptensinya dalam bidang pedagogik, bahkan dalam Permendiknas nomor 16 tahun 2007 bahwa salah satu kompetensi inti guru yang berkaitan dengan pedagogik adalah dapat mengembangkan kurikulum mata pelajaran yang diampu, kompetensi tersebut diantaranya:

1) Memahami prinsip-prinsip pengembangan kurikulum; 
2) Menentukan tujuan pembelajaran yang diampu;

3) Menentukan pengalaman belajar yang sesuai untuk mencapai tujuan pembelajaran yang diampu;

4) Memilih materi pembelajaran yang diampu yang terkait dengan pengalaman belajar dan tujuan pembelajaran;

5) Menata materi pembelajaran secara benar sesuai dengan pendekatan yang dipilih dan karakteristik peserta didik; dan

6) Mengembangkan indikator dan instrumen penilaian.

\section{Menganalisis Materi}

Menganalisis materi bukan hanya dapat dilakukan dengan melihat buku pelajaran, tetapi juga bisa didapatkan dengan melihat berbagai penelitian yang telah disajikan oleh para ahli, sehingga dengan begitu guru dapat memahami materi secara komprehensif. Hal ini penting dilakukan untuk mengantisipasi hambatan belajar yang muncul, sehingga konsep pengetahuan yang diterima guru baik dari penelitian maupun dari buku ajar menjadi satu kesatuan utuh yang bisa diajarkan kepada siswa, sehingga tidak terjadi kesenjangan yang terjadi antara bayangan konsep yang terbentuk pada siswa, guru, dan scientific conception, atau menurut Suryadi (2018) hal tersebut dinamakan dengan Zone of Concept Image Different (ZCID).
Materi yang diperoleh guru baik dalam buku pelajaran maupun berbagai penelitian harus disusun berdasarkan alur belajar siswa (learning trajectory), hal ini untuk mempermudah guru dalam mengajarkan materi tersebut. Menurut Maloney \& Confrey (2013) menjelaskan bahwa learning trajectory dapat menjadi fondasi penilaian untuk melihat kemajuan siswa dan mengidentifikasi kelemahan siswa secara individu maupun kelompok sehingga guru dapat menentukan solusi yang tepat dalam mengatasi kelemahan tersebut.

\section{Hubungan Timbal Balik Guru-Siswa}

Hubungan timbal balik antara guru dan siswa menjadi kunci dalam pembelajaran, guru harus memahami berbagai respon siswa yang muncul pada sata pembelajaran baik respon siswa yang bisa memahami materi pelajaran ataupun siswa yang mengalami kesulitan belajar, respon tersebut harus diantisipasi sehingga hal tersebut akan meminimalisir hambatan yang dialami siswa. Antisipasi respon tersebut harus dimuat dalam perencanaan pembelajaran sebagai bentuk bantuan guru kepada siswa, atau dalam teroinya Vygotsky hal tersebut dinamakan dengan scaffolding.

Dalam menyusun perencanaan pembelajaran, guru harus memperhatikan betul tingkat perkembangan berpikir siswa, karena hal itu akan berpengaruh terhadap pemerolehan pengetahuan yang akan didapatkan siswa. Menurut Piaget (Hill, 2009) bahwa tingkat perkembangan siswa sekolah dasar berada pada tahap operasi konkret, hal ini didasarkan pada 
penelitiannya yang menjelaskan bahwa anak yang berumur 7-11 tahun berada pada tahapan perkembangan operasi konkret, dimana anak mampu mengklasifikasi, mengkombinasi dan membandingkan serta mampu mengungkap hubungan yang ada antara suatu hirarki. Maka pembelajarannya harus diarahkan kepada hal-hal yang bersifat konkret. Selain itu, Piaget menjelaskan bahwa anak berpikir dengan cara yang sama sekali berbeda dengan orang dewasa, maka dalam mendesain alur belajar dalam perencanaan pembelajaran harus disesuaikan dengan tingkat perkembangan kognitif anak.

Komponen-komponen yang dimuat dalam segitiga didaktis harus disusun secara sistematis sebagai bagian dari perencanaan pembelajaran, Salah satu faktor keberhasilan sebuah pembelajaran ditentukan dalam kesungguhan guru dalam membuat perencanaan pembelajaran. Menurut Kilpatrick, Swafford, \& Findell (Mulyana, Turmudi, \& Juandi, 2014) bahwa guru yang efektif sangat memahami bahwa dalam merencanakan pembelajaran dibutuhkan upaya yang sungguh-sungguh, sehingga berbagai kemungkinan dapat dituliskan dalam perencanaan tersebut.

Menurut Permendikbud No. 22 Tahun 2016 bahwa ada beberapa hal penting yang menjadi bahan pertimbangan dalam merencanakan pembelajaran diantaranya adalah:

a. Perbedaan individual peserta didik.

Perbedaan karakteristik yang harus guru perhatikan pada saat menyusun prosedur pembelajaran antara lain kemampuan awal, tingkat intelektual, bakat, potensi, minat, motivasi belajar, kemampuan sosial, emosi, gaya belajar, kebutuhan khusus, kecepatan belajar, latar belakang budaya, norma, nilai, dan/atau lingkungan peserta didik.

b. Partisipasi aktif peserta didik.

Tujuan dari sebuah pembelajaran adalah membuat siswa belajar, pembelajaran yang baik adalah ketika siswa dapat mengikuti proses belajar secara aktif.

c. Berpusat pada peserta didik untuk mendorong semangat belajar, motivasi, minat, kreativitas, inisiatif, inspirasi, inovasi dan kemandirian.

Guru harus mendorong pembelajaran agar berorientasi kepada siswa atau berpusat pada siswa. Menurut Surwajo, Maryatun, \& Kusumadewi, (2012) menjelaskan bahwa student centered learning adalah pembelajaran yang menempatkan peserta didik sebagai pusat dari proses belajar. Dengan begitu, siswa akan semangat dan termotivasi untuk belajar.

d. Pengembangan budaya membaca dan menulis yang dirancang untuk mengembangkan kegemaran membaca, pemahaman beragam bacaan, dan berekspresi dalam berbagai bentuk tulisan.

Penelitian yang dilakukan oleh Programme for International Students Assesment (PISA) pada tahun 2015 bahwa Indonesia berada pada peringkat 64 dari 72 negara, dan pada tahun 2018 
Indonesia berada pada peringkat 72 dari 77 negara, program PISA tersebut untuk melihat tingkat kemampuan literasi siswa baik dalam membaca, matematika dan sains. Dengan data tersebut bahwa bahwa budaya membaca di Indonesia masih sangat rendah, sehingga guru perlu merangsang pembelajaran agar siswa termotivasi untuk giat dalam membaca.

e. Pemberian umpan balik dan tindak lanjut RPP memuat rancangan program pemberian umpan balik positif, penguatan, pengayaan, dan remedi.

Umpan balik dan tindak lanjut merupakan hal yang penting untuk di rencanakan Fenomena dilapangan menunjukan bahwa siswa yang mendapatkan penguatan oleh guru dalam kegiatan pembelajaran memiliki motivasi belajar yang tinggi serta terpacu untuk melakukan pekerjaan (Sulaiman, 2014) begitu juga dengan pengayaan dan remedy akan memperbaiki hasil belajar siswa

f. Penekanan pada keterkaitan dan keterpaduan

Keterkaitan dan keterpaduan harus disusun secara sistematis meliputi kompetensi dasar, materi pembelajaran, kegiatan pembelajaran, indikator pencapaian kompetensi, penilaian, dan sumber belajar dalam satu keutuhan pengalaman belajar. g. Mengakomodasi pembelajaran tematikterpadu, keterpaduan lintas mata pelajaran, lintas aspek belajar, dan keragaman budaya

h. Dalam kurikulum 2013, pembelajaran harus dapat dipadukan antara mata pelajaran, aspek belajar dan keragaman budaya sehingga pembelajaran menjadi holistic.

\section{Perencanaan Pembelajaran dengan Menggunakan Didactical Design Research \\ Didactical design research (DDR) menjadi} sebuah terobosan baru sebagai sebuah inovasi pembelajaran khususnya terhadap panduan dalam menyusun pembelajaran secara lengkap, hal-hal yang bersifat esensial terkait proses pembelajaran dimuat pada lesson design. Adapun beberapa langkah sederhana yang harus disiapkan guru dalam membuat lesson design adalah sebagai berikut:

a. Menganalisis berbagai pengetahuan tentang materi yang akan dipelajari;

b. Menyusun silabus pembelajaran yang akan dikembangkan berkaitan dengan kompetensi dasar yang akan diajarkan;

c. Menyusun tujuan pembelajaran dan instrumen pembelajaran;

d. Menyusun alur belajar siswa;

e. Membuat seperangkat bahan ajar dan tugas belajar siswa;

f. Membuat berbagai prediksi respon siswa yang muncul saat pembelajaran;

g. Mengantisipasi berbagai prediksi respon siswa yang muncul; dan

h. Mengembangkan desain didaktis. 
Adapun langkah tersebut dijelaskan pada gambar dibawah ini:

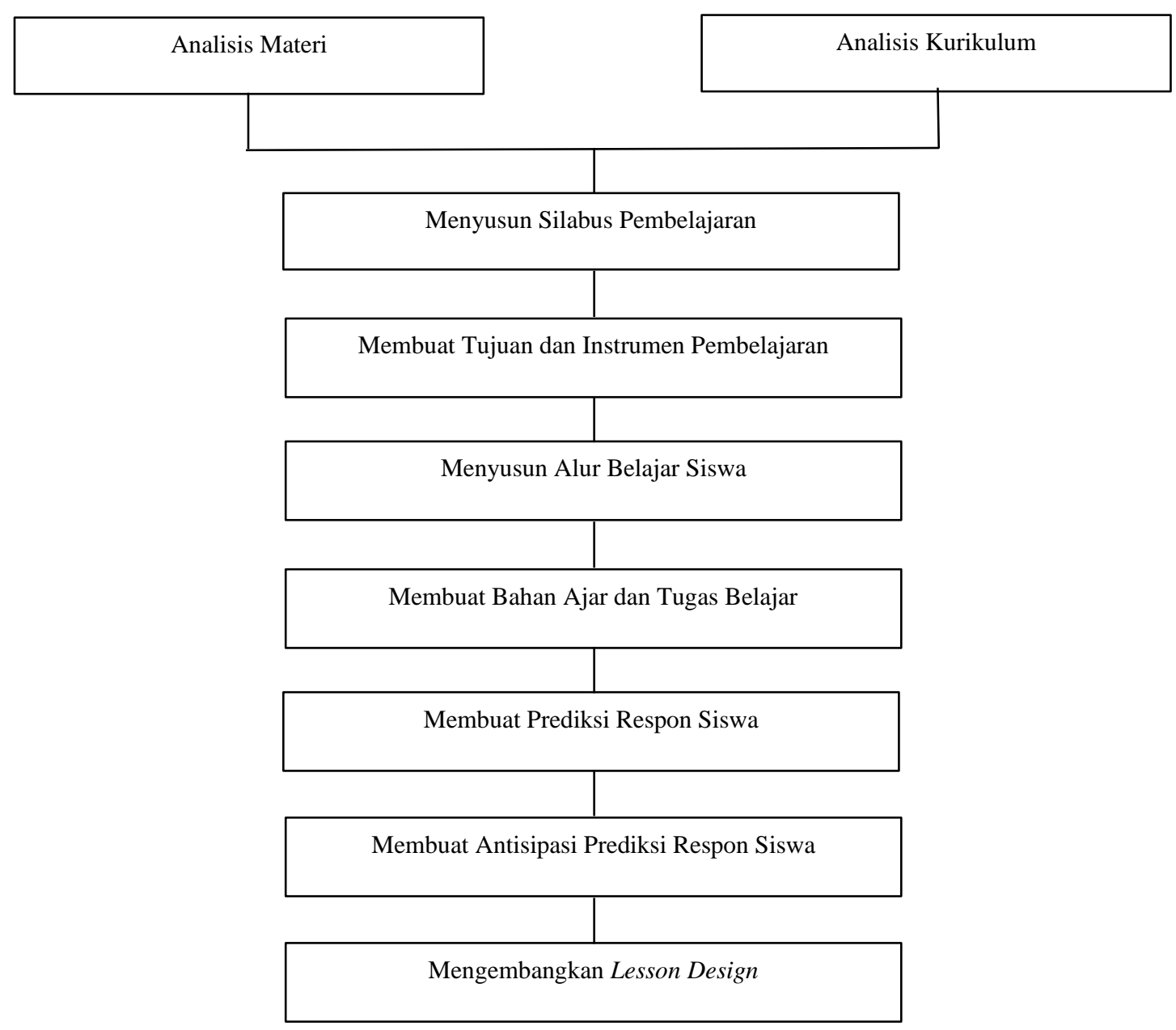

Gambar 4. Alur dalam membuat lesson design/perencanaan pembelajaran

Perencanaan yang dihasilkan di atas masih implementasi perencanaan pembelajaran, bersifat hipotetik, dan harus terus sehingga guru dapat menyempurnakan disempurnakan. Guru dapat menerapkan hasil perencanaan pembelajaran tersebut merevisi desain yang telah dibuat dan menganalisis desain yang telah diterapkan kesesuaian respon yang muncul dengan hasil

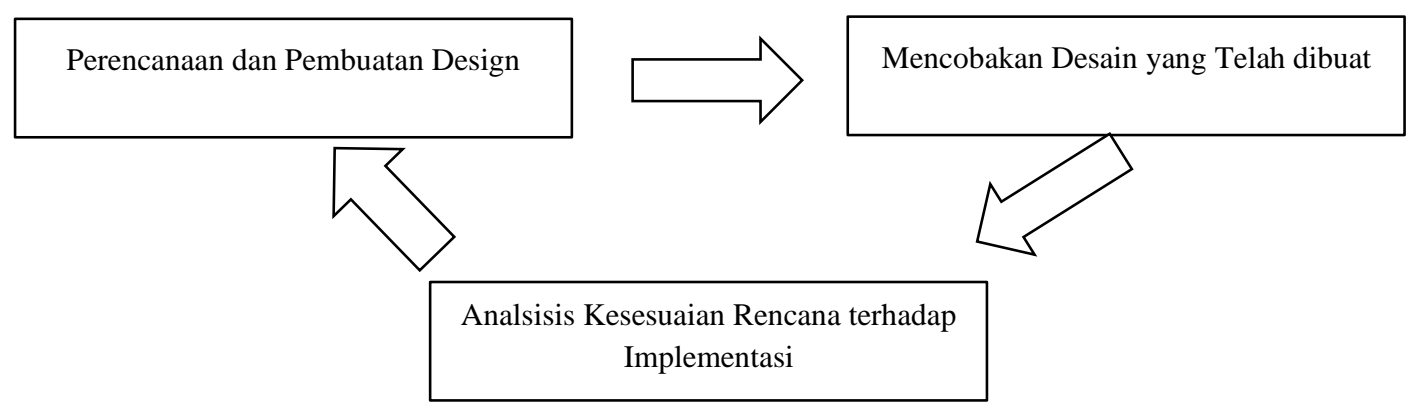

Gambar 5. Alur dalam Membuat Revisi Perencanaan Pembelajaran 
Dengan mengikuti alur pada gambar di atas, guru dapat membuat perencanaan pembelajaran yang sesuai dengan kondisi dan kebutuhan siswa sehingga pembelajaran yang dihasilkan akan bermakna (meaningful learning).

\section{Kesimpulan}

Inovasi dan reformasi pembelajaran harus dilakukan oleh guru. Menurut Goda, et al (2017) bahwa dalam menghadapi tantangan abad 21, guru harus menemukan formula yang tepat untuk dapat diterapkan kepada siswa, formula ini berkaitan dengan cara siswa dalam memperoleh pengetahuan dalam proses pembelajaran. Menyusun rencana pembelajaran menggunakan didactical desain research menjadi formula baru agar siswa memperoleh pengetahuan yang dibutuhkan, karena keberhasilan siswa dalam proses pembelajaran tidak terlepas dari peran guru dalam menyusun rencana pembelajaran. Disamping guru sebagai fasilitator pembelajaran, guru juga bertindak sebagai arsitek pembelajaran yang bertugas menyusun rencana belajar, semakin detail rencana yang dibuat maka keberhasilan pembelajaran akan tercapai, dan hal inilah yang harus dilakukan guru dalam rangka mengembangkan kompetensinya dalam bidang pedagogik.

\section{Daftar Pustaka}

Abidin, Y. (2015). Pembelajaran Multiliterasi Sebuah Jawaban atas
Tantangan Pendidikan Abad ke-21 dalam Konteks Keindonesiaan. Bandung: Refika Aditama.

Alawiyah, F. (2013). Peran Guru dalam Kurikulum 2013. Aspirasi: Jurnal Masalah-masalah Sosial, 4(1), 65-74.

Goda, Y., Yamada, M., Hata, K., Matsukawa, H., \& Yasunami, S. (2017). Effects of Flipped Jigsaw Collaborative Learning on English as a Foreign Language Learning Anxiety. Lecture Notes in Computer Science, 654-664. doi:10.1007/978-3-31952836-6_69

Gravemeijer, K., \& Cobb, P. (2006). Design Research from a Learning Design Perspective. In van den Akker, et al. (Eds.), Educational Design Research (pp. 45-85). London: Routlege.

Hill, W.F. (2011). Theories of Learning. (Alih bahasa oleh Khozim, M). Bandung: Nusa Media

Komariah, A., \& Satori, D. (2011). Metode Penelitian Kualitatif. Bandung: Alfabeta.

Maloney, A., \& Confrey, J. (2013). A Learning Trajectory Freamwork for The Mathematics Common Core: Turnoneemeth for Interpretation: Instructional Planning and Colaboration. $17^{\text {th }}$ Annual Conference of The Association of Mathematics Teacher Educators. Orlando: AMTE.

Manno, G. (2006). Embodiment and ADidactical Situation in The TeachingLearning of The Perpendicular Straigth Lines Concept. Doctoral Thesis: Faculty 
of Mathematics snd Physics Department of Didactic Mathematics Comenius University Bratislava. Tersedia di: http://math.unipa.it/ grim/thesis_GMan no_06_engl.pdf

Martadiputra, B.A.P. (2013). Modifikasi Model-Eliciting Activities dengan Menggunakan Didactical Design Research untuk Meningkatkan Kemampuan Berpikir Statistis. Jurnal Kependidikan, 43(2), 95-106.

Mulyana, E., Turmudi, \& Juandi, D. (2014). Model Pengembangan Desain Didaktis Subject Specific Pedagogy Bidang Matematika melalui Program Pendidikan Profesi Guru. Jurnal Pengajaran MIPA, 19(2), 141-149.

Nazir, M. (2013). Metode Penelitian. Bogor: Ghala Indonesia.

Peraturan Menteri Pendidikan Nasional Nomor 16 Tahun 2007 tentang Standar Kualifikasi Akademik dan Kompetensi Guru.

Peraturan Menteri Pendidikan dan Kebudayaan Nomor 22 Tahun 2016 Tentang Standar Proses Pendidikan Dasar dan Menengah

Rusman. (2013). Model-model Pembelajaran, Mengembangkan Profesionalisme Guru. Jakarta: Rajawali Press.

Saputri, A.T.W., \& Mawardi. (2017). Pengembangan Desain Pembelajaran Tematik Integratif Berbasis Pendekatan
Contextual Teaching and Learning (CTL) Kelas 4 Sekolah Dasar. Jurnal Ilmiah Pendidikan Dasar, 4(2), 104114.

Sulaiman. (2014). Pengaruh Pemberian Penguatan (reinforcement) oleh Guru Terhadap Motivasi Belajar Siswa di Kelas IV SD Nunggul Lampeuneurut Aceh Besar. Jurnal Pesona Dasar, 2(3), 85-93.

Surwajo., M, IB., \& Kusumadewi, N (2012).

Penerapan Student Centered Approch pada Pembelajaran Taman Kanak-kanak Kelompok B (Studi Kasus di Sekolah Laboratorium Rumah Citta. Jurnal Pendidikan Anak, 1(1), 79-102.

Suryadi, D. (2010). Didactical Design Research (DDR) dalam Pengembangan Pembelajaran Matematika. Prosiding Seminar Nasional MIPA. Universitas Negeri Malang.

Suryadi, D. (2018). Landasan Filosofis Penelitian Desain Didaktis (DDR). Bandung: Departemen Pendidikan Matematika UPI

Trilling, B \& Fadel, C. (2009). 21st-century skills: learning for life in our times. United States: Jossey-Bass A Wiley Imprint.

Zendrato, J. (2016). Tingkat Penerapan Perencanaan Pembelajaran dalam Melaksanakan Pembelajaran di Kelas Suatu Studi Kasus di SMA Dian Harapan Jakarta. Scholaria, 6(2), 58-7 